\title{
Conceito de Número: Uma Contribuição da Análise Comportamental da Cognição ${ }^{1}$
}

\author{
Paulo Sérgio Teixeira do Prado 2 \\ Universidade Estadual Paulista \\ Júlio Cesar DeRose \\ Universidade Federal de São Carlos
}

\begin{abstract}
RESUMO - Fundamenta-se o presente estudo na análise comportamental da cognição, cujas formulações permitem compreender o conceito de número como uma rede de relações entre estímulos e/ou entre estímulos e respostas. O desempenho de seis crianças de três a sete anos de idade e uma adolescente portadora da Síndrome de Down foi analisado em uma série de tarefas consideradas pré-requisitos para aprendizagens matemáticas mais complexas. Para isso, foi utilizada uma versão informatizada do procedimento de discriminação condicional em um contexto de matching to sample. As relações presentes, ausentes e as não bem estabelecidas no repertório dos sujeitos foram graficamente representadas em diagramas que configuram-se como que retratos do repertório individual. Tal recurso facilita o planejamento do ensino estratégico de umas poucas relações com vistas à emergência das relações ausentes e/ou o fortalecimento daquelas nas quais o sujeito apresenta desempenho pobre, de modo a completar a rede. A guisa de conjeturas, apresentam-se sugestões de intervenção.
\end{abstract}

Palavras-chave: conceito de número; equivalência de estímulos; rede de relações; discriminação condicional; informática e educação.

\section{The Concept of Number: A Contribution From Behavioral Analysis of Cognition}

\begin{abstract}
The present study has its foundation in the behavioral analysis of cognition, whose formulations allow to comprehend number concept as a network of relations among stimuli and/or among stimuli and responses. The performance of six children from three to seven years old and one adolescent with Down's Syndrome was analised in a serie of tasks considered pre-requisites to more complex mathematical learning. For this a computerized version of conditional discrimination procedure was used within a context of matching to sample. The present relations as well as the absent ones and the bad established ones in the subject's repertoires were graphically represented in diagrams that configures itself as individual repertoire's portrait. This resource facilitates the planning of strategical teaching of some relations on purpose to do the emergence of the absent relations and/or to strenghten those relations in which the subject present poor performance, in a way to complete the net. Suggestions of intervention are made.
\end{abstract}

Key words: number concept; stimulus equivalence; network relations; conditional discrimination; computing and education.

A literatura sobre conceito de número tem se tornado cada vez mais extensa e diversificada. Nela, encontram-se desde estudos que analisam habilidades isoladas, por exemplo, a contagem (Beckwith \& Restle, 1966) ou apenas um de seus componentes (Potter \& Levy, 1968); até elaborações teóricas complexas tal como a de Piaget e Szeminska (1941/1981), cujo conceito de conservação provocou um intenso debate (por exemplo: Gelman, 1969; Wohlwill, 1960; Zimiles, 1963) e gerou uma respeitável quantidade de pesquisas (ver revisão em Macedo, 1972, 1975; e alguns estu-

1 Este trabalho é produto de uma replicação, com um número menor de sujeitos, da pesquisa que fundamentou a dissertação de mestrado do primeiro autor. Contamos com a valiosa colaboração de Jane Laís Yumi Uemura e Débora Cristina Pereira, ambas bolsistas PIBIC/CNPq Agradecemos ao Centro de Convivência Infantil (CCI) e ao Centro de Orientação Educacional (COE), ambos da Unesp-Maríla, que nos possibilitaram a realização da coleta dos dados com seus alunos.

2 Endereço: Universidade Estadual de São Paulo - Marília. Departamento de Psicologia da Educação. Campus Universitário. Av. Hygino Muzzi Filho, 737. CEP: 17525-900 Marília - SP.

E-mail: pradopst@marilia.unesp.br dos experimentais sobre o tema em Macedo \& Amêndola, 1980; Macedo \& Assis, 1984). Encontram-se, também, trabalhos sobre a hierarquia das habilidades que compõem aquele conceito (Schaeffer, Eggleston \& Scott, 1974; Spradlin, Cotter Stevens \& Fiedman, 1974; Wang, Resnick \& Boozer, 1971; Wohlwill, 1960) e outros que investigam capacidades numéricas em bebês (por exemplo: Gelman, 1972; Gelman \& Meck, 1983; Starkey, Spelke \& Gelman, 1983; Strauss \& Curtis, 1981; Wynn, 1990, 1992a; 1992b, entre muitos outros) sobre os quais discutem com mais profundidade Fayol (1990/1996), Geary (1994), Ottoni (1993) e Prado (1995).

Da perspectiva da Análise do Comportamento, Drachenberg $(1973 ; 1990)$ considerou que um determinado valor numérico seria uma propriedade abstrata do conjunto. Sendo esse valor mantido constante em conjuntos de objetos diferentes, a propriedade generalizar-se-ia para todos os grupos de mesmo valor, significando a abstração do conceito. Para ensinar os conceitos de um a dez, a autora adotou um procedimento de modificação gradual no controle de certos aspectos de um estímulo para outro (fading in), aplicando-o em uma situação de pareamento com o modelo (matching to 
sample). Dos 13 sujeitos de dois a seis anos, apenas um completou a longa série de 10 passos (cada um com várias etapas e um grande número de tentativas); e cada sujeito fez, em média, 140 sessões de treino.

Parece-nos que para o reconhecimento de um valor comum a grupos distintos de objetos é indispensável o uso da contagem. Esta, por sua vez, pressupõe que se saiba os nomes dos números, a ordem destes, a relação entre quantidades e nomes de números, entre outras habilidades. Melhor desempenho poderia ter sido apresentado pelos sujeitos do estudo acima se, a partir de uma análise operacional da contagem, esta habilidade lhes houvesse sido ensinada.

Baseados também nos pressupostos behavioristas, mas já empregando conhecimento incipiente sobre a produção de desempenhos emergentes, Gast, VanBiervliet e Spradlin (1979) trabalharam com três crianças com idade entre oito e 11 anos com atraso de desenvolvimento, e quatro pré-escolares normais de $3 \mathrm{a} 3 \mathrm{~m}$ (três anos e três meses) a 4a7m. Antes da intervenção, todos eram capazes de: (1) reconhecer os numerais; (2) separar subconjuntos de conjuntos totais a partir de números ditados; e (3) também a partir de numerais impressos; (4) emparelhar numerais a conjuntos; (5) emparelhar conjuntos a numerais; (6) nomear os numerais; e (7) contar conjuntos totais.

Os valores usados foram de um a seis. A essa classe de estímulos-respostas foi incluído um novo membro: palavranúmero impressa, por meio de um treino no qual reforçavase a seleção de palavras-número a partir de números ditados. O ensino dessa única relação foi suficiente para produzir a emergência de diversas novas relações: emparelhamento de numeral a palavra-número e sua inversa; a seleção de palavras-número dados conjuntos correspondentes e viceversa, e a nomeação das palavras-número. Não houve diferenças entre o desempenho apresentado pelas crianças normais e o daquelas com atraso de desenvolvimento.

Maydak, Stromer, Mackay e Stoddard (1995) investigaram a inter-relação entre classes de estímulos equivalentes e tarefas de produção de seqüência (sequence-production tasks). Os sujeitos foram um homem e uma mulher com grande atraso de desenvolvimento. Em linhas gerais, o experimento consistiu da formação de classes de estímulos equivalentes compostas por nomes de números ditados, numerais e quantidades (conjuntos de pontos). Subseqüentemente, foi realizado um treino de produção de seqüência com as quantidades dois a cinco no qual, dados conjuntos com esses valores dispostos aleatoriamente, o sujeito devia ordenálos selecionando-os do menos para o mais numeroso. Testes posteriores revelaram a emergência da producção de seqüência com os numerais de dois a cinco.

Também aplicando tecnologia de estudos sobre equivalência de estímulos, Lynch e Cuvo (1995) desenvolveram um programa para o ensino de frações. A alunos de sexta e sétima séries que, segundo seus professores, apresentavam dificuldades em tarefas envolvendo frações e números decimais, foram ensinadas as relações: $(\mathrm{A})$ fração $\longrightarrow$ (B) representação pictográfica de fração; e, (B) representação pictográfica $\longrightarrow$ (C) número decimal; um treino $\mathrm{AB}, \mathrm{BC}$; por- tanto. Posteriormente, por meio de testes apropriados, observou-se a emergência de BA e CB (a simetria das relações), AC (a transitividade) e CA (a equivalência). Foi testada, ainda, a generalização com frações de valores correspondentes aos das usadas no treino, com frações e números decimais novos; e a conversão de fração para número decimal e vice-versa em uma prova de tipo papel e lápis.

Do que precede, nota-se que o procedimento de matching to sample é empregado com certa freqüência. $\mathrm{E}$, mais recentemente, tem-se lançado mão de tecnologia que possibilita que o ensino se faça de modo a produzir aprendizagens que vão além daquilo que é diretamente ensinado. Procedimentos oriundos de estudos sobre equivalência de estímulos possibilitam que o ensino de umas poucas relações produzam a emergência de várias outras, ampliando sobremaneira o repertório do aprendiz.

A metodologia usada nas pesquisas pode servir como recurso para a detecção de necessidades individuais de aprendizagem, propiciando a obtenção de informações que subsidiem a elaboração e implementação de estratégias individualizadas de ensino. Identificando-se relações presentes, ausentes e/ou não bem estabelecidas no repertório da criança, pode-se planejar o ensino com vistas à promoção de desempenhos emergentes e a constituição de classes de equivalência.

O presente estudo parte da idéia de que é possível conceber o conceito de número como uma rede de relações estímulo-estímulo e/ou estímulo-resposta, das quais algumas são aprendidas por meio de ensino direto e outras emergentes. O propósito foi o de analisar o status dessa rede no repertório dos sujeitos. Para a efetivação desse objetivo, adaptamos o diagrama de Sidman (1971), por meio do qual foi possível representar graficamente o desempenho de cada criança. Trata-se de um recurso que permite uma rápida e fácil visualização das relações presentes, ausentes e aquelas não bem estabelecidas no repertório individual, constituindo-se um meio que auxilia na formulação de propostas de intervenção.

A rede completa de relações que compõem o conceito de número, tais como analisadas neste estudo, encontra-se esquematicamente representada na Figura 1.

Tal rede poderia ser ampliada com a inclusão de outras tarefas, mas ela representa os pré-requisitos mais elementares para aprendizagens matemáticas mais complexas. Os retângulos representam situações de estímulo e/ou resposta, as setas e as relações entre elas. As setas vão na direção do estímulo modelo para o de comparação ou resposta. O diagrama deve ser lido da seguinte forma: $\mathrm{A} \rightarrow \mathrm{B}$ : dado um número ditado como estímulo modelo, a criança deve selecionar, dentre vários, o numerai correspondente; $\mathrm{A} \longrightarrow \mathrm{C}$ : dado um número ditado, a criança deve selecionar um conjunto com número equivalente de elementos; $\mathrm{B} \longrightarrow \mathrm{C}$ : dado um numeral, a criança deve selecionar, entre vários conjuntos, o de valor correspondente; $\mathrm{B} \longrightarrow \mathrm{D}$ : dado um numeral, a criança deve nomeá-lo; $\mathrm{C} \longrightarrow \mathrm{B}$ : dados um conjunto e vários numerais, a criança deve selecionar, entre estes, aquele que representa o "tamanho" do conjunto; $\longrightarrow$ D: dado um con- 


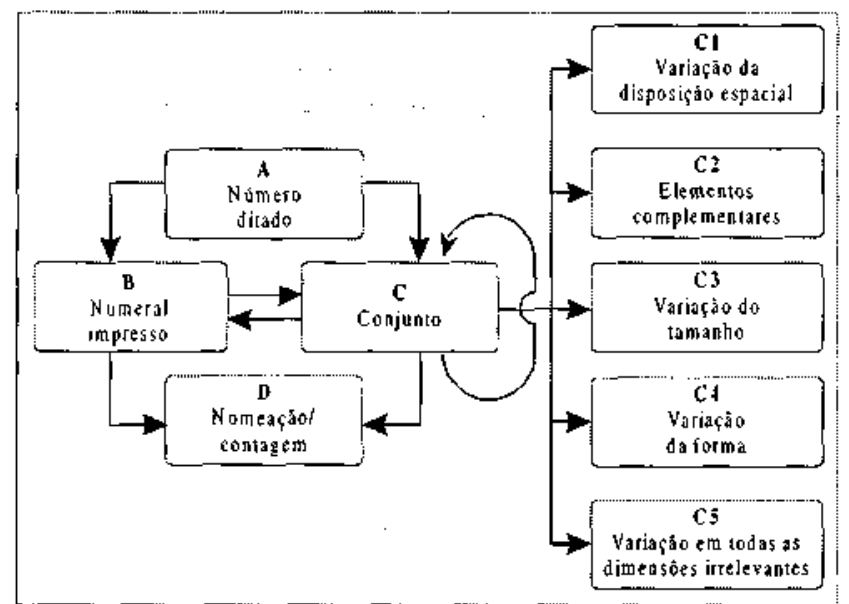

Figura 1 - Diagrama esquemático da rede de relações que compõem o conceito de número tal como analisado neste estudo

junto, a criança deve contar os seus elementos e dizer quantos são; portanto, ela nomeia a quantidade, fazendo-o através de uma resposta intermediária, a contagem. A seta descrevendo um loop, que parte do retângulo $\mathrm{C}$ e retorna para ele mesmo, representa o pareamento de conjuntos sem variações nas dimensões irrelevantes. As setas $\mathrm{C} \longrightarrow \mathrm{Cl}$ a C5 representam o pareamento de conjuntos com variações em diversas dimensões irrelevantes.

\section{Método}

\section{Sujeitos}

Foram sujeitos deste estudo seis crianças normais e uma adolescente portadora da Síndrome de Down. Entre as crianças havia três meninos e três meninas, com idade compreendida entre $3 \mathrm{a} 4 \mathrm{~m}$ e sete anos. Todas eram filhas de funcionários de uma universidade e freqüentavam o Centro de Convivência Infantil (CCI) da Universidade Estadual Paulista (Unesp), Câmpus de Marília, onde eram assistidas por educadoras profissionais. A adolescente portadora da Síndrome de Down, pertencente a uma família de classe média, contava 16 anos de idade à época da realização do estudo. Ela freqüentava o Centro de Orientação Educacional (COE), uma unidade auxiliar da Unesp-Marília, onde recebia educação formal de educadores profissionais e estagiárias do Curso de Pedagogia, ambos ligados à área de Educação Especial.

\section{Situação}

Os sujeitos foram recebidos individualmente ao longo de quatro a seis sessões. Todas as tarefas foram semi-automaticamente ministradas através de um computador. $\mathrm{O}$ sujeito sentava-se a uma mesa diante do monitor de vídeo, sentando-se o experimentador ao seu lado e ligeiramente recuado para trás, fora de seu campo visual, mantendo o teclado sobre suas pernas. O tempo de duração de cada sessão variou entre cinco e dezoito minutos.

\section{Material}

O equipamento usado para a condução das sessões, registro e análise preliminar dos dados, foi um microcomputador AT/486, com monitor de vídeo SVGA. Foi usada também, uma câmera VHS para o registro em vídeo de algumas sessões.

\section{Procedimento}

As atividades escolares transcorriam normalmente durante a pesquisa. Portanto, não houve isolamento das variáveis educacionais que pudessem interferir na aprendizagem do conceito de número.

O procedimento adotado foi o de discriminação condicional, aplicado em um contexto de pareamento com o modelo. Os estímulos gráficos eram apresentados na tela do computador em uma matriz $2 \times 2$, medindo cada janela $12,5 \mathrm{~cm}$ x $9,5 \mathrm{~cm}$. O estímulo modelo, quando visual, era apresentado invariavelmente na janela superior esquerda, cujas bordas eram desenhadas com um traçado diferente do que foi usado nas janelas destinadas à apresentação dos estímulos de comparação.

A seleção dos estímulos, pelos sujeitos, era feita por meio de toque com o dedo. Dependendo da natureza da tarefa, o estímulo modelo podia ser verbal, ditado pelo experimentador. Nesse caso, a janela modelo permanecia "vazia" e, ao toque da criança sobre ela, apresentavam-se os estímulos de comparação. A seguir, o experimentador fornecia o modelo falado e o sujeito selecionava uma das alternativas. Em tarefas cuja resposta fosse de nomeação ou contagem, o estímulo era apresentado na janela modelo e as outras permaneciam vazias.

Simulou-se o uso de tela sensível ao toque. As respostas do sujeito eram reproduzidas pelo experimentador através da digitação de teclas específicas do teclado numérico. Às teclas 7 e 9 correspondiam, respectivamente, as janelas superiores esquerda e direita; e, às teclas 1 e 3 , as janelas inferiores esquerda e direita. Quando as respostas eram verbais, se corretas, o experimentador pressionava a tecla 9, programada para registrar a resposta como correta e acionar a apresentação do feedback; caso contrário, pressionava qualquer outra tecla e a resposta era registrada como incorreta.

O programa previa a apresentação de feedback para todas as respostas corretas. Estas eram consequienciadas por meio da apresentação, pelo próprio computador, do desenho de uma mão fechada com o polegar estendido, simultaneamente às primeiras notas de uma de duas melodias ao fundo, apresentadas randomicamente. Durante as primeiras tentativas, o experimentador fazia elogios ao sujeito, informando-o que o desenho e a música indicavam que a resposta estava correta. Respostas incorretas eram seguidas por um intervalo de três segundos com a tela apagada, ao término do qual apresentavam-se os estímulos da tentativa seguinte.

A posição da alternativa correta foi randomizada entre as tentativas, e o número de vezes em que ela apresentava-se em cada posição foi balanceado, nunca se repetindo por mais do que duas vezes na mesma posição em tentativas consecutivas. 


\section{I- Treino Preparatório}

Uma fase inicial consistiu de um treino preparatório, cujas finalidades foram familiarizar os sujeitos com a situação e ensinar-lhes as respostas necessárias para a fase seguinte. Esse treino foi composto por três blocos de nove tentativas cada. Os estímulos utilizados foram nove figuras reconhecíveis, de modo que um mesmo estímulo nunca se repetia como modelo em um mesmo bloco.

Em cada um dos blocos foram treinadas, respectivamente, as tarefas de emparelhamento por semelhança física (matching de identidade), seleção a partir de modelo falado e nomeação de figuras. O critério de desempenho foi de $100 \%$ de acertos. Se este não fosse alcançado na primeira apresentação do bloco, ele era automaticamente reapresentado. Se ainda assim o critério não fosse atingido, a sessão era interrompida e o treino retomado em dia posterior.

\section{II- Análise do conceito de número}

Uma série de tarefas foi administrada em três passos. Nos Passos 1 e 2, cada tarefa foi composta por um bloco de nove tentativas (exceção feita para a tarefa de pareamento conjunto / conjunto no Passo 2, como se verá adiante) e foram usados, como estímulos, desenhos de objetos supostamente conhecidos pelos sujeitos. No Passo 3, os estímulos foram formas geométricas e a tarefa consistiu de um bloco de 45 tentativas. Todos os passos serão detalhadamente descritos a seguir.

Quando os estímulos eram conjuntos, a disposição dos elementos obedecia a arranjos ordenados $3 / 4$ disposição simétrica dos itens; e não ordenados $3 / 4$ disposição assimétrica dos itens.

Nas tentativas envolvendo conjuntos, estabeleceu-se o seguinte critério: os estímulos de comparação tinham valores consecutivos; e, em um terço das tentativas, a alternativa correta seria o conjunto com maior número de elementos; em outro terço, o conjunto menor; e, em outro, o de valor intermediário. Quando o estímulo modelo fosse um conjunto unitário ou com nove elementos, os estímulos de comparação tinham os valores imediatamente acima ou abaixo, respectivamente.

Valores de um a cinco foram distribuídos randomicamente entre as cinco primeiras tentativas de cada bloco, enquanto que os valores maiores apresentavam-se nas tentativas finais. Este critério não foi adotado no Passo 3, como se verá abaixo.

Não foi estabelecido nenhum critério de desempenho para que os sujeitos avançassem nas tarefas, nem tampouco foi adotado qualquer procedimento de correção de respostas incorretas ou qualquer outro destinado à instalação de respostas, uma vez que o objetivo era tão somente o de verificar, e não ensinar, determinadas habilidades relacionadas ao comportamento matemático.

No Passo 1, os conjuntos foram sempre simétricos. A primeira tarefa era de nomeação dos numerais. Ou seja, dado um numeral (apresentado na janela modelo) o sujeito devia nomeá-lo. A tarefa seguinte era a de contagem: dado um conjunto, cujos elementos eram figuras presumivelmente reconhecíveis, o sujeito devia contá-los e dizer quantos eram. Não havia limite de tempo, nem restrições quanto a autocorreções. Foi considerada a resposta final, independentemente do processo por meio do qual ela era produzida. A próxima tarefa era a de emparelhamento de números ditados (modelos) com conjuntos (comparações). A seguir, havia uma sequiência de tentativas de seleção de numerais a partir de números ditados, outra de tentativas de pareamento de conjuntos com numerais; e sua inversa, a de numerais com conjuntos. Cada bloco foi composto por nove tentativas, as quais foram em número de 54 no total.

O Passo 2 foi composto por sete blocos que totalizaram 63 tentativas. Embora bastante semelhantes, os Passos 1 e 2 têm diferenças importantes: a maioria das tarefas foi reaplicada, sendo exceção a de seleção de numerais a partir de números ditados e a de nomeação de numerais, que não se repetiram; e a de equiparação de conjuntos (ou pareamento conjunto / conjunto), que foi incluída. Todas as tarefas envolveram conjuntos, e estes foram apresentados em arranjos assimétricos em quatro delas, no que diferiram do Passo 1, em que foi usado apenas o arranjo simétrico.

$\mathrm{Na}$ tarefa de equiparação de conjuntos, foram manipuladas três dimensões de estímulo, operada sempre sobre os estímulos de comparação, ao longo de três blocos sucessivos de nove tentativas cada. No primeiro, os conjuntos foram todos simétricos, o que eqüivale a dizer que as dimensões irrelevantes tamanho, forma e disposição espacial dos elementos foram mantidas constantes, variando-se apenas a quantidade (dimensão relevante). No segundo bloco variouse, além da quantidade de elementos, também a sua disposição espacial. No bloco final, usaram-se figuras fisicamente dessemelhantes para os estímulos modelo e de comparação. Dessa maneira, além das dimensões que sofreram variação nos blocos anteriores, variou-se, também, a forma dos elementos que compunham os conjuntos. No entanto, para evitar uma possível dificuldade extra para os sujeitos efetuarem a correspondência numérica entre os conjuntos em função da ausência de similaridade física, os estímulos eram elementos complementares. Exemplificando, quando o estímulo modelo era um conjunto de copos, os de comparação eram conjuntos de canudinhos, ou cadeados e chaves, anzóis e peixes, e assim por diante.

Note o leitor que o emprego de elementos complementares como estratégia de controle de algumas dimensões irrelevantes não permite inferências precisas sobre como a dimensão tamanho controla as respostas, uma vez que variando essa dimensão junto com a forma, não seria possível, no momento da análise, isolar os efeitos de cada uma. Essas dimensões foram controladas mais sistematicamente em outro passo, como veremos a seguir.

No Passo 3, os estímulos foram formas geométricas: círculo, estrela, losango, quadrado, retângulo, semi-círculo (fechado), triângulo e trapézio; que variaram em tamanho de acordo com os valores: pequeno, médio e grande. A natureza da tarefa foi única: equiparação de conjuntos de acordo 
com sua equivalência numérica (emparelhamento conjunto / conjunto). Esse passo foi incluído para que se pudessem analisar possíveis diferenças de controle pelas dimensões tamanho, forma e disposição espacial. Houve nove tentativas para cada uma dessas dimensões, cada uma correspondendo a uma quantidade de um a nove. Quando variava uma dimensão, as outras eram mantidas constantes. Entre os estímulos de comparação, havia sempre um dos incorretos correspondendo ao modelo com relação à dimensão irrelevante manipulada na tentativa.

Para evitar que os sujeitos viessem a apresentar respostas sob controle da diferença (oddity), 18 tentativas foram incluídas sendo que, em metade delas, não havia variação de nenhuma dimensão, exceto a quantidade. Na outra metade, todas as dimensões irrelevantes variavam ao mesmo tempo. As tentativas foram apresentadas em uma seqüência randômica.

\section{Resultados}

Dois momentos distintos, porém inter-relacionados, comporão a atual seção: inicialmente serão apresentados os dados de cada um dos sujeitos em cada tarefa particular. A seguir, traçaremos perfis individuais do repertório das habilidades estudadas, para o que exploraremos uma possibilidade oferecida pelo diagrama de rede de relações proposto por Sidman (1971), empregando-o de modo a representar, graficamente, a dimensão quantitativa do desempenho dos sujeitos. A partir desses perfis, conjeturaremos sobre possíveis estratégias de ensino com vistas à promoção de desempenhos emergentes.

\section{Análise individual}

As Tabelas 1 e 2 resumem o desempenho das crianças em cada tarefa. Nas colunas, estão agrupados os sujeitos, em ordem crescente de idade. Sua identificação é feita por uma sigla composta por uma (ou duas) letra(s) do nome em caixa alta, um número correspondente à idade, e uma letra minúscula: $m$ ou $f$, indicando o sexo. Nas linhas, encontramse as tarefas que foram administradas em cada passo.

$\mathrm{Na}$ Tabela 1, a ordem de apresentação dos passos e de suas respectivas tarefas reproduz a seqüência em que foram realizadas. No Passo 1, em todas as tarefas envolvendo conjuntos $(2,3,5$ e 6$)$, estes foram simétricos. No Passo 2, Conjunto / conjunto I, refere-se ao emparelhamento de conjuntos sem variação em dimensões irrelevantes; Conjunto / conjunto II, ao emparelhamento de conjuntos com variação da disposição espacial dos elementos; e, Conjunto / conjunto III, ao emparelhamento de conjuntos com elementos complementares, conforme descrição apresentada no Método. Ainda no Passo 2, com exceção da Tarefa 2, em todas as outras os conjuntos foram assimétricos.

O Passo 3, constituiu uma única tarefa: pareamento de conjuntos com variação sistemática nas dimensões irrelevantes tamanho, forma e disposição espacial dos elementos. Os resultados são resumidos na Tabela 2 .

Cada linha na tabela acima representa um grupo de nove tentativas, nas quais foi manipulada uma determinada dimensão. Essa separação foi feita para facilitar a análise. Porém, na realidade, as tentativas foram apresentadas em ordem aleatória. Foram usadas formas geométricas e houve nove tentativas para cada uma das variações (uma tentativa para cada valor de um a nove). Incluíram-se ainda 18 tentativas, sendo que, em nove delas, não houve qualquer variação em dimensões irrelevantes e, nas outras nove, todas as dimensões variaram simultaneamente. As tentativas, em um total de 45, foram apresentadas em ordem randômica.

Comparando-se o desempenho dos sujeitos por faixa etária (Tabelas 1 e 2), observa-se que o das crianças de três anos esteve ao nível do acaso na maioria das tarefas. Os sujeitos de quatro anos saíram-se melhor, mas com maiores

Tabela 1 - Desempenho dos sujeitos, em porcentagem de acertos, nas tarefas dos Passos 1 e 2.

\begin{tabular}{|c|c|c|c|c|c|c|c|}
\hline \multirow[b]{2}{*}{ Tarefas (relação) } & \multicolumn{7}{|c|}{ Sujeitos } \\
\hline & V3m & M3f & A4f & $\mathbf{P 4 m}$ & MC6f & VN7m & Mal6f \\
\hline \multicolumn{8}{|l|}{ Passo 1} \\
\hline 1. Nomeação dos numerais (BD) & 11,1 & 00,0 & - & 100,0 & 100,0 & 100,0 & 100,0 \\
\hline 2. Contagem /simétricos/ (CD) & 66,6 & 33,3 & - & 77,7 & 55,5 & 100,0 & 88,8 \\
\hline 3. Número ditado $\rightarrow$ conjunto (AC) & 77,7 & 33,3 & 77,7 & 100,0 & 100,0 & 100,0 & 100,0 \\
\hline 4. Número ditado $\rightarrow$ numeral $(\mathrm{AB})$ & 22,2 & 44,4 & 88,8 & 100,0 & 100,0 & 100,0 & 100,0 \\
\hline 5. Conjunto $\longrightarrow$ numeral $(\mathrm{CB})$ & 44,4 & 33,3 & 55,5 & 77,7 & 88,8 & 88,8 & 100,0 \\
\hline 6. Numeral $\rightarrow$ conjunto (BC) & 55,5 & 22,2 & 55,5 & 100,0 & 100,0 & 100,0 & 100,0 \\
\hline \multicolumn{8}{|l|}{ Passo 2} \\
\hline 1. Contagem /assimétricos/ (CD) & 66,6 & 22,2 & 33,3 & 100,0 & 100,0 & 100,0 & 100,0 \\
\hline 2. Conjunto $\longrightarrow$ conjunto I $(\mathrm{CC})$ & 55,5 & 11,1 & 77,7 & 100,0 & 100,0 & 100,0 & 100,0 \\
\hline 3. Conjunto $\longrightarrow$ conjunto II (CC1) & 22,2 & 33,3 & 22,2 & 77,7 & 77,7 & 88,8 & 77,7 \\
\hline 4. Conjunto $\longrightarrow$ conjunto III (CC2) & 11,1 & 33,3 & 44,4 & 77,7 & 55,5 & 88,8 & 88,8 \\
\hline 5. Conjunto $\longrightarrow$ numeral $(\mathrm{CB})$ & 55,5 & 33,3 & 55,5 & 100,0 & 100,0 & 100,0 & 100,0 \\
\hline 6. Número ditado $\rightarrow$ conjunto (AC) & 44,4 & 55,5 & 44,4 & 88,8 & 100,0 & 100,0 & 100,0 \\
\hline 7. Numeral $\longrightarrow$ conjunto $(\mathrm{BC})$ & 33,3 & 33,3 & 55,5 & 100,0 & 100,0 & 100,0 & 100,0 \\
\hline
\end{tabular}

As letras entre parênteses na primeira coluna devem ser lidas em referência à Figura 1. 
Tabela 2 - Desempenho dos sujeitos, em porcentagem de acertos, no Passo 3. As letras entre parênteses na primeira coluna devem ser lidas em referência à Figura 1.

\begin{tabular}{|c|c|c|c|c|c|c|c|}
\hline \multirow[b]{2}{*}{ Passo 3 (relação) } & \multicolumn{7}{|c|}{ Sujeitos } \\
\hline & V3m & M3f & A4f & $\mathbf{P} 4 \mathbf{m}$ & MC6f & VN7m & Ma16f \\
\hline Nenhuma variação em dimensões irrelevantes $(C C)$ & 55,5 & 55,5 & 88,8 & 100,0 & 100,0 & 88,8 & 100,0 \\
\hline Variação da forma (CC4) & 33,3 & 33,3 & 77,7 & 88,8 & 77,7 & 100,0 & 100,0 \\
\hline Variação da disposição espacial (CC1) & 11,1 & 11,1 & 22,2 & 77,7 & 88,8 & 88,8 & 100,0 \\
\hline Variação de todas as dimensões irrelevantes (CC5) & 33,3 & 22,2 & 66,6 & 77,7 & 77,7 & 100,0 & 100,0 \\
\hline
\end{tabular}

- As letras entre parênteses, na primeira coluna, devem ser lidas em referência à Figura 1.

diferenças individuais. Acima dessa idade (não há dados de crianças na faixa dos cinco anos), o desempenho é virtualmente perfeito, embora com oscilações ocasionais, sobretudo em tarefas envolvendo contagem.

No Passo 3 (Tabela 2), de modo geral, mantém-se a tendência verificada nos passos anteriores. Mais particularmente, evidencia-se que a porcentagem de respostas corretas foi notavelmente inferior entre os sujeitos de três e quatro anos quando a dimensão irrelevante manipulada foi a disposição espacial dos elementos.

Convém recordar que, no Passo 3, quando variava uma dimensão irrelevante, as demais eram mantidas constantes (com exceção das tentativas em que todas as dimensões variavam simultaneamente, e para aquelas em que não houve variação em dimensões irrelevantes). Ou seja, quando o tamanho ou a forma dos estímulos de comparação eram diferentes do estímulo modelo, sua disposição espacial era igual. Considerando que aparentemente essa dimensão exerce forte controle sobre as respostas das crianças, isso explicaria a maior proporção de respostas corretas naquelas tentativas, à semelhança do que ocorreu com todos os sujeitos na Tarefa 2 do Passo 2, exceto M3f (cf. Tabela 1).

Quando variavam todas as dimensões irrelevantes, ou seja, quando a única relação possível entre os estímulos modelo e de comparação era a quantidade, o meio para se chegar à escolha correta era a contagem. $\mathrm{O}$ sujeito que não apresentava tal habilidade teve um desempenho pobre nessas tentativas.

Ainda duas observações a serem feitas. Em primeiro lugar, não houve diferenças marcantes no desempenho dos sujeitos em função da simetria ou assimetria dos conjuntos, conforme constata-se em uma comparação entre os Passos 1 e 2 (Tabela 1). Finalmente, embora o procedimento tenha sido tal que todas as respostas corretas foram conseqüenciadas, não se produziu efeito de aprendizagem. Tal efeito refletir-se-ia em um aumento gradual na proporção de respostas corretas ao longo das tarefas, o que significaria uma "contaminação" dos dados.

\section{Analisando os perfis e conjeturando sobre estratégias de ensino}

Para ser eficiente, qualquer intervenção deve ser planejada com base em um diagnóstico preciso. Propomos, a seguir, um método de análise individualizada baseada no per- fil do repertório de cada sujeito, a partir do qual conjeturamos sobre estratégias de ensino que levem em conta as relações presentes para a promoção da emergência das relações ausentes e/ou o fortalecimento das não bem estabelecidas. Levar a efeito tais estratégias é um objetivo ulterior do projeto, no qual se insere o presente estudo e onde são feitas apenas conjeturas sobre elas.

O diagrama de rede de relações de Sidman (1971) pode ser usado como forma de expressão quantitativa do desempenho de cada sujeito, compondo um perfil individual do repertório sob análise. Isso pode ser feito tomando-se o diagrama da Figura 1, alterando-se o traçado das setas que ligam os retângulos como forma de representar faixas de porcentagem de acertos. Setas com linha cheia são usadas para representar um bom desempenho. Setas com linha tracejada representam desempenho regular, e a ausência de setas significa a ausência da relação.

Os conceitos ruim, regular e bom foram formulados a partir dos escores dos sujeitos nas tarefas. Todas elas foram compostas por nove tentativas. A maioria foi aplicada duas vezes: uma no Passo 1 e outra no Passo 2, no qual os conjuntos tinham arranjos assimétricos (com exceção do pareamento de conjuntos sem variação das dimensões irrelevantes). Dado que não houve grandes diferenças nos escores em função do arranjo dos conjuntos, cada tarefa é considerada como tendo dezoito tentativas.

Com relação às tarefas que foram aplicadas somente uma vez, são consideradas nove tentativas. São elas: no Passo 1, nomeação dos numerais e seleção de numeral impresso a partir de número ditado; no Passo 2, pareamento de conjuntos com elementos complementares; e no Passo 3, pareamento de conjuntos com variação das dimensões tamanho, forma e de todas as dimensões irrelevantes.

Desse modo, consideramos ruim o desempenho dos sujeitos que obtiveram de $0 \%$ a $38,9 \%$ de acertos (7/18); regular, de $44,4 \%(8 / 18$ ou $4 / 9)$ a $83,3 \%(15 / 18)$; e bom, de $88,9 \%$ $(8 / 9$ ou $16 / 18)$ a $100 \%$.

Normalmente, adotam-se critérios mais rigorosos para a análise do desempenho em procedimentos de discriminação condicional. Neste estudo, que versa sobre o conceito de número, entretanto, é importante adotar um critério que permita discriminar o desempenho das crianças com as diferentes quantidades. Algumas delas, destacadamente as menores de seis anos, podem apresentar a rede de relações completa. Porém, somente com valores de um a quatro. Nesses 
a)
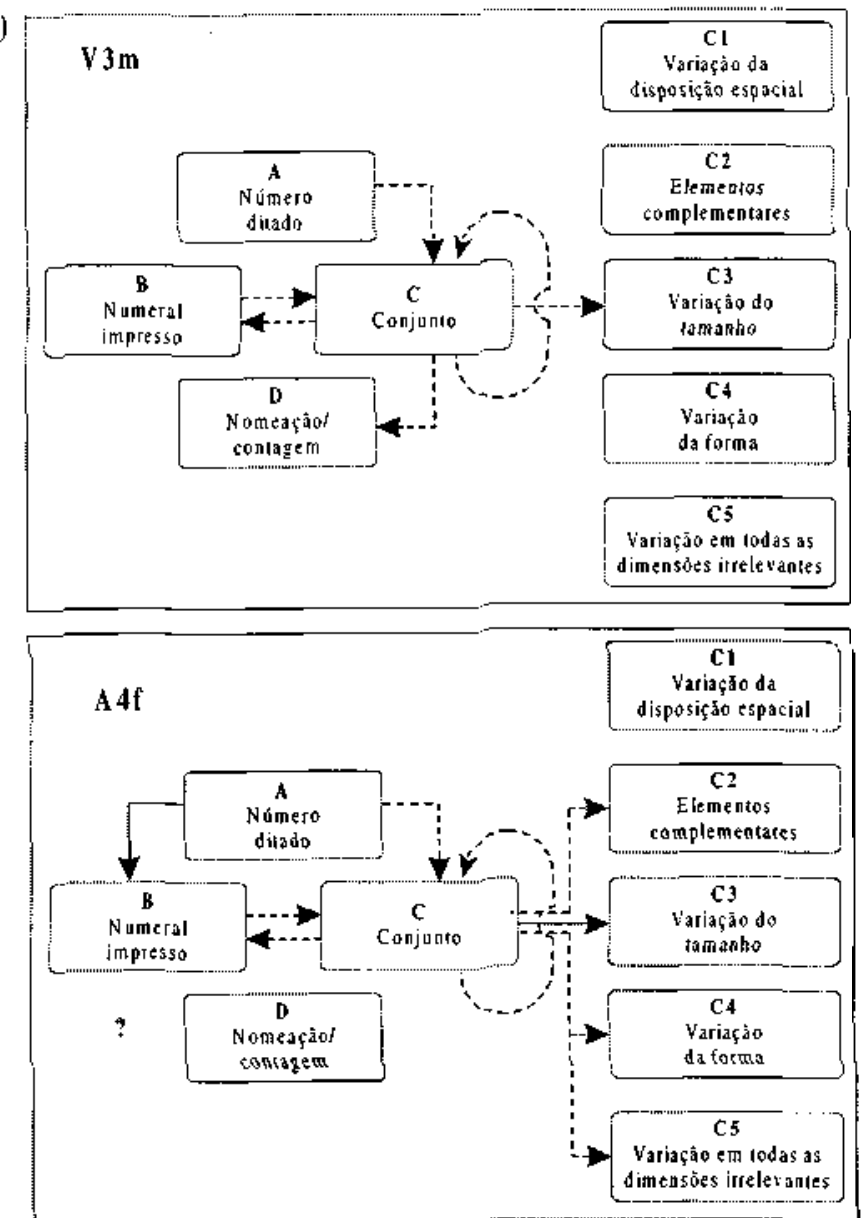

b)

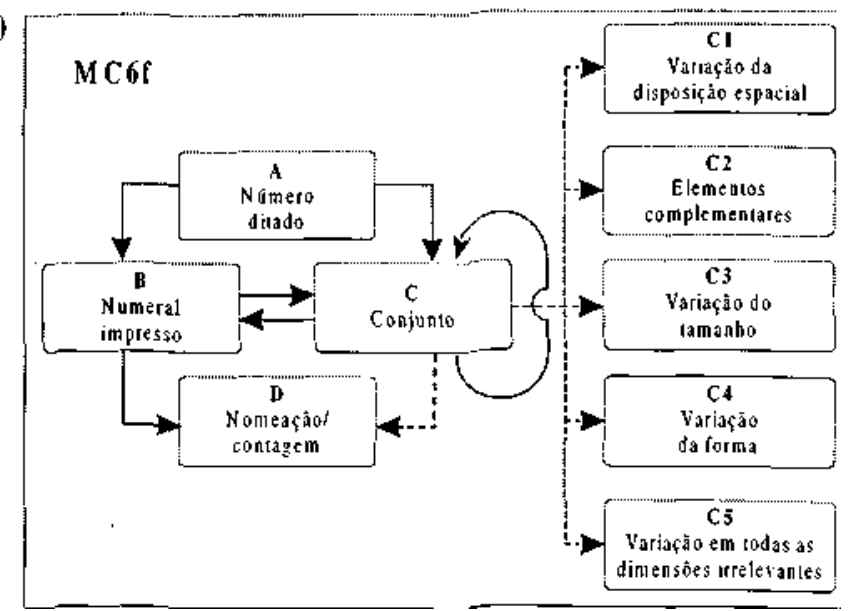

casos, o sujeito teria quatro acertos em nove tentativas $(44,4 \%)$.

Um erro em nove tentativas, ou dois em dezoito $(88,9 \%)$, pode ocorrer ocasionalmente não significando, contudo, que o sujeito não tenha o conceito. Assim, a faixa nos parece justa para considerar bom o desempenho. Vejamos, então, o perfil de cada sujeito, como ilustrado na Figura 2.

$\mathrm{O}$ sujeito $\mathrm{V} 3 \mathrm{~m}$ não apresenta as relações $\mathrm{AB}$ (número ditado / numeral) e BD (nomeação dos numerais). No entanto, verifica-se que apresenta as relações BC (numeral / conjunto) e CB (conjunto / numeral). Como isso pode ocor-

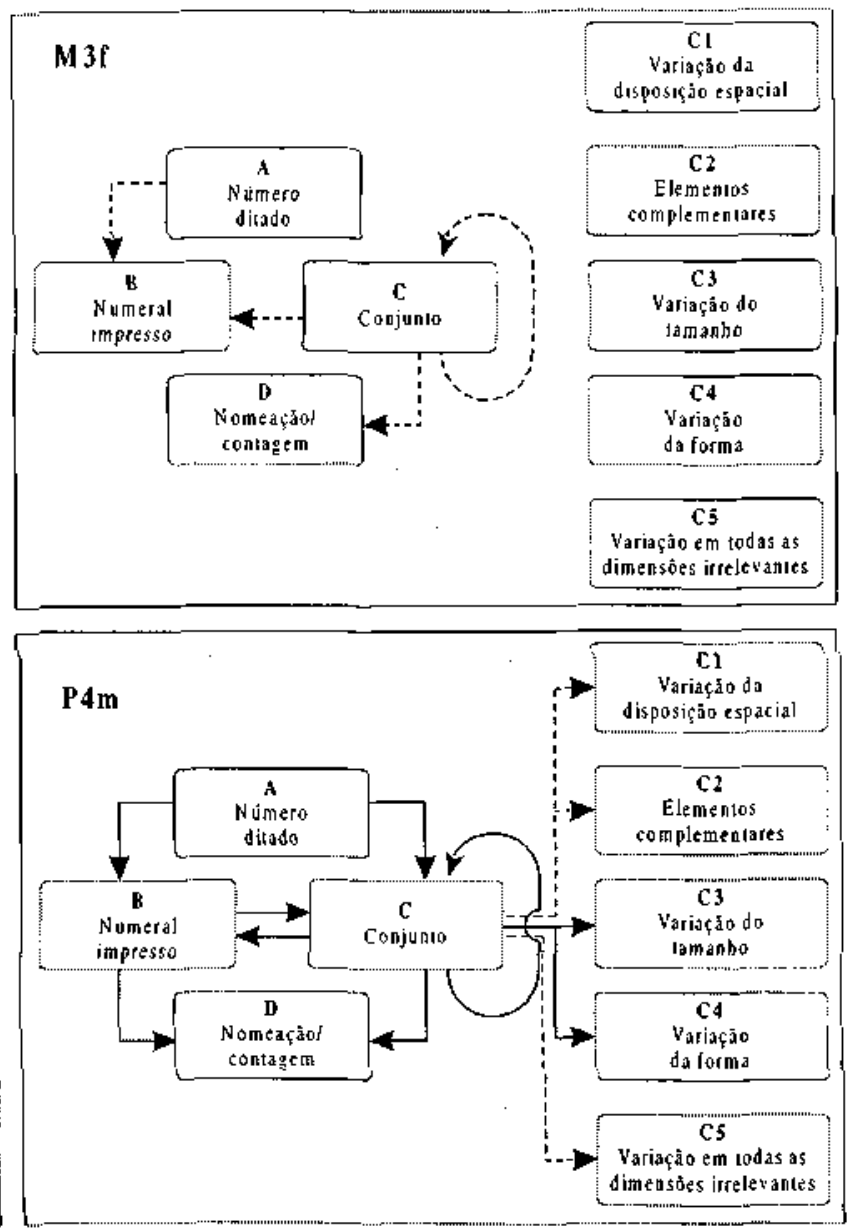

- Setas com linha cheia representam um bom desempenho.

- Setas com linha tracejada representam um desempenho regular.

- A ausência de setas representa a ausência de relação.

Figura 2 - Diagramas esquemáticos representando os perfis individuais do repertório pré-aritmético dos sujeitos.

rer? Como afirmamos acima, de acordo com o critério adotado, a partir de $44,4 \%$ de acertos, consideramos o desempenho regular. Ora, recordemos que em cada tentativa havia três alternativas de escolha, o que significa 33,3\% de chances de acerto. Se o sujeito apresentasse um desempenho regular nas relações $\mathrm{AB}$ e $\mathrm{BD}$, este estaria de acordo com o desempenho apresentado nas relações $\mathrm{BC}$ e $\mathrm{CB}$, pois demonstraria que o sujeito faz a correspondência numeral / conjunto e vice-versa com valores até quatro. Visto que não foi o que ocorreu, seus acertos nas tentativas de emparelhamento numeral / conjunto e sua simétrica, conjunto - numeral, estiveram ao nível do acaso.

No que diz respeito às relações AC (número ditado / conjunto) e CD (contagem), V3m apresenta um desempenho coerente. Sua habilidade para contar, no entanto, estando em um nível ainda regular, não lhe permite um bom desempenho na equiparação de conjuntos $(\mathrm{CCj}$ a $\mathrm{C}$ ). Note que na tarefa de emparelhamento conjunto - conjunto sem variação nas dimensões irrelevantes (CC), é possível que se apresente um bom desempenho mesmo sem possuir a habilidade de contar; pois, neste caso, a forma conferida aos conjuntos 
pela distribuição de seus elementos é que controla a resposta. Bastaria ao sujeito a habilidade generalizada de equiparar objetos de acordo com sua semelhança física \{matching generalizado de identidade).

Considerando a forma como se apresenta a rede de relações do sujeito $\mathrm{V} 3 \mathrm{~m}$, podemos supor que o ensino da relação $\mathrm{AB}$ e o fortalecimento da relação $\mathrm{CD}$ seriam suficientes para que emergissem todas as demais relações, completando a rede. Senão vejamos: Aprendendo a selecionar os numerais a partir de seus respectivos nomes ditados (AB), o sujeito tomar-se-ia apto a nomear os numerais por si mesmo. Há evidências experimentais sobre isso em DeRose, Souza, Rossito e DeRose (1992); DeRose, Souza e Hanna (1996); Ferrari, DeRose e Mcllvane (1993). Estando presentes as relações $\mathrm{AB}$ e $\mathrm{BD}$, e melhorando a habilidade de contagem, seria altamente provável a emergência da seleção de conjuntos a partir de números ditados, os emparelhamentos numeral - conjunto e conjunto / numeral e a equiparação de conjuntos independente de variações em dimensões irrelevantes.

A rede de relações é bastante incompleta no repertório de M3f. As poucas relações que exibe, dada a forma como se apresentam, parecem expressar acertos ao acaso. Se assim não fosse, por que apresentaria a relação $C B$ e não sua simétrica $\mathrm{BC}$, por exemplo? A mesma estratégia de ensino sugerida para V3m deveria ser adotada, também, com M3f. $\mathrm{O}$ ensino (ou fortalecimento) de $\mathrm{AB}$ e $\mathrm{CD}$ produziria a emergência de $\mathrm{AC}, \mathrm{BD}, \mathrm{BC}, \mathrm{CB}$ e $\mathrm{CC}_{1}$ a $\mathrm{C}_{5}$.

Infelizmente, não temos os dados de nomeação dos numerais (BD) do sujeito A4f. Os dados de contagem expressam o desempenho do sujeito apenas na tarefa com conjuntos assimétricos, pois também não dispomos dos dados de seu desempenho em contagem com conjuntos simétricos. Considerando-se seu desempenho na relação $A B$, é possível que em BD apresentasse um desempenho, pelo menos, regular.

No que diz respeito à relação $\mathrm{CD}, \mathrm{A} 4 \mathrm{f}$ fez metade das tentativas dos colegas, o que contribuiu para que diminuíssem suas chances de acertos. De qualquer forma, todas as tarefas de emparelhamento conjunto / conjunto requeriam contagem e, na maioria delas, o sujeito não obteve bons escores. Podemos supor que as respostas de A4f, nas tarefas de equiparação de conjuntos $\mathrm{CC}$ e $\mathrm{CC}_{2}$ a $\mathrm{C}_{5}$, estiveram sob controle da dimensão disposição espacial. Note que quando essa dimensão varia (CC), seu desempenho é pobre.

$\mathrm{O}$ ensino cuidadoso das habilidades requeridas na contagem parece suficiente para que se complete, em seu repertório, a rede de relações que compõe o conceito de número.

Os sujeitos $\mathrm{P} 4 \mathrm{~m}$ e MC6f apresentam redes bastante completas. Lembrando que as relações $\mathrm{CC}_{1}$ a $\mathrm{C}_{5}$ foram testadas em um único bloco, $\mathrm{P} 4 \mathrm{~m}$ pode ter se cansado e isto interferido em seu desempenho. Algo semelhante pode ter ocorrido com MC6f, embora seu desempenho na relação CD deixe alguma dúvida. No entanto, nos dois casos parece suficiente o planejamento de situações em que possam praticar suas habilidades de contagem e de equiparação de conjuntos. Por exemplo, na escola, pedindo-lhes que ajudem a pôr a mesa na hora do lanche: o número de copos igual ao de coleguinhas, e outras situações semelhantes.

Os repertórios dos demais sujeitos não foram representados. Isto porque como apresentaram um bom desempenho em todas as relações, os diagramas resultantes seriam todos idênticos ao da Figura 1. São crianças que, na nossa compreensão, já possuem os pré-requisitos indispensáveis para que sejam introduzidas nas noções da aritmética elementar.

\section{Discussão}

No presente trabalho, analisamos o conceito de número na perspectiva do paradigma de redes de relações. Para levarmos a efeito tal análise, elaboramos um instrumento computadorizado. Também propusemos uma forma de representação gráfica do repertório individual pré-aritmético dos sujeitos, adaptado do diagrama de Sidman (1971). Esse recurso constitui-se uma alternativa de análise do estado da rede de relações, o que por sua vez favorece a tomada de decisões sobre as melhores estratégias de ensino a serem adotadas. Sobre isso, foram apresentadas conjeturas, ficando para um estudo futuro sua implementação.

\section{Referências}

Beckwith, M. \& Restle, F. (1966). Process of enumeration. Psychological Review, 73(5), 437-444.

DeRose, J.C.C., Souza, D.G. \& Hanna, H. (1996). Teaching reading and spelling: Stimulus equivalence and exclusion. Journal of Applied Behavior Analysis, 29(4), 450-469.

DeRose, J.C.C., Souza, D.G., Rossito, A.L. \& DeRose, T.M.S. (1992). Stimulus equivalence and generalization in reading after matching to sample by exclusion. Em S.C. Hayes \& L.J. Hayes (Orgs.), Understanding verbal relations (pp. 69-82). Reno, EUA: Context Press.

Drachenberg, H.B. (1973). Programação das etapas que levam à modificação gradual no controle de certos aspectos de um estímulo para outro (fading) na situação de "escolha de acordo com o modelo". Ciência e Cultura, 25(1), 44-53.

Drachenberg, H.B. (1990). Aquisição do conceito de quantidade: programação de um procedimento de "Escolha Conforme o Modelo " para crianças. Assis: FCLA-HUCITEC.

Fayol, M. (1996). A criança e o número: da contagem à resolução de problemas. R. (S. Leoni, Trad.) Porto Alegre: Artes Médicas. (Trabalho original publicado em 1990)

Ferrari, C, DeRose, J.C.C. \& Mcllvane, W.J. (1993). Exclusion vs. selection training of auditory-visual conditional relations. Journal of Experimental Child Psychology, 56, 49-63.

Gast, D.L., VanBiervliet, A. \& Spradlin, J.E. (1979). Teaching number-word equivalences: A study of transfer. American Journal of Mental Deficiency, 83(5), 524-527.

Geary, D.C. (1994). Children's mathematical development: Research and practical applications. Washington, DC: American Psychological Association.

Gelman, R. (1969). Conservation acquisition: A problem of learning to attend to relevant attributes. Journal of Experimental Child Psychology, 7(2), 167-187. 
Gelman, R. (1972). Logical capacity of very young children: Number invariance rules. Child Development. 43, 75-90.

Gelman, R. \& Meek, E. (1983). Preschoolers' counting: Principles before skill. Cognition, 13, 343-359.

Lynch, D.C. \& Cuvo, A.J. (1995). Stimulus equivalence instruction of fraction-decimal relations. Journal of Applied Behavior Analysis, 28(2), 115-126.

Macedo, L. (1972). Aquisição da noção de conservação por intermédio de um procedimento de escolha conforme o modelo. Tese de Doutorado, Universidade de São Paulo, São Paulo.

Macedo, L. (1975). Procedimentos de treino da noção de conservação. Psicologia, 1(1), 21-47.

Macedo, L. \&Amêndola, M.B. (1980). Aquisição da noção de conservação por intermédio de um procedimento de escolha do ímpar (oddity learning). Psicologia, 6(1), 25-42.

Macedo, L. \& Assis, M.B.A.C. (1984). Aquisição da noção de conservação por intermédio de aprendizagem discriminativa ou operatória. Psicologia, 10(3), 11-26.

Maydak, M., Stromer, R., Mackay, H.A. \& Stoddard, L. (1995). Stimulus classes in matching to sample and sequence production: The emergence of numeric relations. Research in Developmental Disabilities, 16(3), 179-204.

Ottoni, E.B. (1993). Dos limites do contar ao contar sem limites: um estudo sobre o desenvolvimento da competência numérica e da noção de infinitude na criança. Tese de Doutorado, Universidade de São Paulo, São Paulo.

Piaget, J. \& Szeminska, A. (1981). A gênese do número na criança (3* ed.). CM. Oiticica, Trad.) Rio de Janeiro: Zahar Editores. (Trabalho original publicado em 1941)

Potter, M.C. \& Levy, E.I. (1968). Spatial enumeration without counting. Child Development, 39, 265-273.
Prado, P.S.T (1995). O conceito de número: uma análise com base no paradigma de rede de relações. Dissertação de Mestrado, Universidade Federal de São Carlos, São Carlos.

Schaeffer, B., Eggleston, V.H. \& Scott, J.L. (1974). Number development in young children. Cognitive Psychology, 6, 357-379.

Sidman, M. (1971). Reading and auditory-visual equivalences. Journal of Speech and Hearing Research, 14, 5-13.

Spradlin, J.E., Cotter, V.W., Stevens, C. \& Friedman, M. (1974). Performance of mentally retarded children on pre-arithmetic tasks. American Journal of Mental Deficiency, 78(A), 397-403.

Starkey, P., Spelke, E.S. \& Gelman, R. (1983). Detection of intermodal numerical correspondences by human infants. Science, 222, 179-181.

Strauss, M.S. \& Curtis, L.E. (1981). Infant perception of numerosity. Child Development, 52, 1146-1152.

Wang, M.C, Resnick, L.B. \& Boozer, R.F. (1971). The sequence of development of some early mathematical behaviors. Child Development, 42, 1767-1778.

Wohlwill, J.F. (1960). A study of the development of the number concept by scalogram analysis. Journal of Genetic Psychology, 97, 345-377.

Wynn, K. (1990). Children's understanding of counting. Cognition, 36(2) 155-193.

Wynn, K. (1992a). Addition and subtraction by human infants Nature, 358, 749-750.

Wynn, K. (1992b). Children's acquisition of number words and the counting system. Cognitive Psychology, 24, 220-251.

Zimiles, H. (1963). A note on Piaget's conception of conservation. Child Development, 34, 691-695.
Recebido em 27.04.1999

Primeira decisão editorial em 08.10.1999

Versão final em 04.01.2000

Aceito em 17.03.2000 